\title{
Characteristics of Patients Admitted to the Intensive Care Unit in a Spanish Cohort of Influenza Patients
}

\author{
Zamarrón $\mathrm{E}^{1,4 *}$, Mangas $\mathrm{A}^{1,4}$, Carpio $\mathrm{C}^{1,4}$, Figueira $\mathrm{JC}^{2,4}$, Arribas $\mathrm{JR}^{3,4}$, Álvarez-Sala Walther $\mathbf{R}^{1,4}$, \\ Prados $\mathrm{C}^{1,4}$, Ríos $\mathrm{JJ}^{4}$, Díaz-Pollán $\mathrm{B}^{4}$, Madero $\mathrm{D}^{4}$, Cobas $\mathrm{J}^{4}$, Forés $\mathrm{G}^{4}$, Baquero $\mathrm{F}^{4}$, Pinto $\mathrm{MJ}^{4}$, Pastor \\ $\mathrm{M}^{4}$, Ramos $\mathrm{H}^{4}$, García $\mathrm{S}^{4}$, Martins $\mathrm{G}^{4}$, Robustillo $\mathrm{A}^{4}$ and San Juan $\mathrm{I}^{4}$ \\ ${ }^{1}$ Pulmonary Department, Spain \\ ${ }^{2}$ Intensive Care Unit, Spain \\ ${ }^{3}$ Infectious Diseases-Internal Medicine Department, La Paz University Hospital, IdiPAZ, Universidad Autónoma Madrid, Spain \\ ${ }^{4}$ Seasonal influenza working group of La Paz University Hospital, Spain
}

*Corresponding author: Ester Zamarrón de Lucas, Pulmonary Department, Hospital Universitario La Paz, IdiPaz, Paseo de la Castellana 261, 28046-Madrid, Spain

\begin{tabular}{|c|c|}
\hline ARTICLE INFO & ABSTRACT \\
\hline Received: 背 July 22, 2020 & Introduction: influenza is a highly contagious infection that constitutes a public \\
\hline Published: 蔧 July 29, 2020 & $\begin{array}{l}\text { health problem due to its rapid transmission and associated high morbimortality. The } \\
\text { disease can cause complications that require intensive care unit [ICU] admission and it }\end{array}$ \\
\hline
\end{tabular}

Citation: Zamarrón E, Mangas A, Carpio C, Figueira JC, Arribas JR, et al., Characteristics of Patients Admitted to the Intensive Care Unit in a Spanish Cohort of Influenza Patients. Biomed J Sci \& Tech Res 29(2)2020. BJSTR. MS.ID.004765.

Keywords: Influenza, Intensive Care Unit, Characteristics, Risk Factors

Methodology: single-centre, observational, cross-sectional, retrospective study of patients admitted for influenza to La Paz University Hospital during the 2013-2014 and 2014-2015 seasons.

Result: 182 patients were admitted during the 2013-14 and 2014-15 seasons, 18 of whom were admitted to the ICU. These were younger and $83 \%$ were male. The length of hospital stay was longer in those who required ICU admission $[25 \pm 20$ vs $11 \pm 9$ days] $[\mathrm{p}=0.013]$. Eight patients developed bacterial superinfection, nine pneumonia, nine adult respiratory distress syndrome [ARDS] and eight multiorgan failure. Four died. Five were vaccinated and 14 received treatment with antivirals. In 17 [100\% of the typed cases] virus A infection was confirmed, of which six were H1N1.

Conclusion: Male sex and the development of ARDS are two independent risk factors for ICU admission. These patients have more complications, a longer hospital stay and more influenza A than those in conventional hospitalisation.

\section{Highlights}

a) Male sex and the development of acute distress respiratory syndrome are two independent risk factors for ICU admission.

b) Admission in the Intensive Care Unit occurs in 10\% of all those hospitalised for influenza.

c) Influenza confirmed patients show higher detection rates of influenza A virus. 


\section{Introduction}

Influenza is a highly contagious disease that constitutes a public health challenge every year due to its high transmission and associated morbidity and mortality [1]. Every year 3-5 million serious cases are registered leading to 250,000-500,000 deaths annually [1]. Although influenza viruses cause a self-limiting disease with symptoms such as fever, cough, runny nose, and general malaise, this disease can be complicated by the development of pneumonia and acute respiratory failure, intensive care unit [ICU] admission, and even the need for mechanical ventilation [2,3]. There are risk groups for these complications, including pregnancy $[2,4]$, obesity [2,5,6], advanced age [7-9], chronic diseases and immunosuppression [6]. However, in the 2009 influenza A pandemic, one of most relevant findings was the high mortality rate among healthy children and young adults $[7,10,11]$. Flu is responsible for $1.3 \%$ of total admissions to the ICU throughout the year. If we consider the flu season only, this percentage increases to $3.4 \%$ of total admissions to the unit [12]. In the 2013-2014 epidemic, the Spanish Influenza Surveillance System [SISS] reported a total of 2,475 severe confirmed virus cases, of which $25.9 \%$ were admitted to the ICU [13]. In the 2014-2015 season, of the 1,724 severe cases reported and hospitalised, 33\% were admitted to the ICU [14].

We therefore face the challenge of influenza every year and we must be prepared. It is essential to understand the characteristics of severe cases since they generate both high morbidity and mortality and healthcare costs. As far as we know, published data are scarce concerning the characteristics of severe hospitalised confirmed influenza cases admitted to the ICU for complications associated with seasonal flu, and most published studies refer to the influenza A H1N1 pandemic in 2009 [2,6]. For this reason, our objective has been to analyse the characteristics of patients admitted to our centre in the 2013-2014 and 2014-2015 seasons, which are two of the seasons with the highest morbidity and mortality in recent years in Spain, and those that have required admission to the ICU.

\section{Patients and Methods}

\section{Design}

Single-centre, observational, cross-sectional, retrospective study of adults hospitalised due to influenza at La Paz University Hospital in the 2013-2014 and 2014-2015 influenza seasons. Data were collected from medical records and from the documents collected by the SISS for each patient.
Variables recorded were both demographic, such as age and sex, and clinical. Clinical variables included development of secondary bacterial pneumonia that required a compatible clinical picture and consolidation on a chest x-ray, complication with influenzarelated bacterial superinfection, development of multiorgan failure and acute respiratory distress syndrome (ARDS). We also recorded recognised risk factors in the SISS [13], such as chronic lung disease (CLD) [unspecified], heart disease [unspecified], diabetes mellitus, chronic kidney disease (CKD) [unspecified], immunodeficiency [treatment with more than $10 \mathrm{mg}$ of prednisone in the last 30 days or other immunosuppressors, human immunodeficiency virus [HIV] or other diseases considered], morbid obesity [body mass index $\left.[\mathrm{BMI}]>40 \mathrm{~kg} / \mathrm{m}^{2}\right]$, liver disease and pregnancy. Length of hospital stay and ICU admission, number of deaths during hospitalisation, antiviral treatment and its duration, and influenza subtypes were also detailed.

\section{Statistical Analysis}

We conducted a descriptive analysis of the various study variables. Data were expressed as mean [standard deviation] or number [percentage]. The comparison of qualitative variables was performed using the Chi-squared test after creating various contingency tables, and quantitative variables were compared using Student's t-test. If the variables did not meet normality criteria, nonparametric tests were used. Multivariate analysis was performed using logistic regression tests. We considered differences of $\mathrm{p}<0.05$ to be statistically significant. Statistical analysis was performed with SPSS statistical software, IBM SPSS Statistics version 19.0.0 [SPSS Inc., Chicago, IL, USA].

\section{Ethical Aspects}

The study was approved by the research ethics committee of La Paz University Hospital [PI-2850].

\section{Result}

182 hospitalised confirmed influenza cases were identified in the 2013-14 and 2014-15 seasons. In 2013-2014, 59 patients [32.4\% of the total cohort] were included, 36 of whom were male [61\%] with a mean age of $67 \pm 18$ years. In 2014-2015, 123 patients were admitted, 60 of whom were male [48.8\%] with a mean age of $76 \pm 15$ years, which was older than in the 2013-2014 season [p = $0.02]$. Of the total number of patients in both seasons, 18 patients [10.2\%] required admission to the ICU (Appendix Table 1).

Appendix Table 1: Comparison between patients admitted in the 2013-2014 and 2014-2015 seasons.

\begin{tabular}{|c|c|c|c|}
\hline & $2013-2014(n, \%)$ & 2014-2015 (n, \%) & $\mathbf{p}$ \\
\hline Total of patients & 59 & 123 & - \\
\hline \multicolumn{4}{|c|}{ Baseline Characteristics } \\
\hline Age, yrs & $67 \pm 18$ & $76 \pm 15$ & 0.02 \\
\hline Sex, male & $36(61.0)$ & $60(48.8)$ & 0.12 \\
\hline Chronic lung disease, n (\%) & $35(59.3)$ & $43(35.0)$ & 0.002 \\
\hline
\end{tabular}




\begin{tabular}{|c|c|c|c|}
\hline Diabetes mellitus, n (\%) & $13(22.0)$ & $24(19.8)$ & 0.73 \\
\hline Chronic kidney disease, n (\%) & $15(25.4)$ & $15(12.3)$ & 0.026 \\
\hline Chronic heart disease, $\mathrm{n}(\%)$ & $31(52.5)$ & $62(51.7)$ & 0.91 \\
\hline Immunodeficiency, n (\%) & $17(28.8)$ & $38(30.9)$ & 0.77 \\
\hline Obesity, n (\%) & $10(16.9)$ & $10(8.2)$ & 0.78 \\
\hline Chronic liver disease, n (\%) & $6(10.2)$ & $10(8.1)$ & 0.65 \\
\hline Pregnancy, n (\%) & $0(0)$ & $0(0)$ & - \\
\hline \multicolumn{4}{|c|}{ Complications } \\
\hline ICU admission, $\mathrm{n}(\%)$ & $8(13.6)$ & $10(8.5)$ & 0.29 \\
\hline Pneumonia, n (\%) & $25(43.1)$ & $29(23.8)$ & 0.08 \\
\hline Bacterial superinfection, $\mathrm{n}(\%)$ & $17(48.6)$ & $58(52.3)$ & 0.77 \\
\hline ARDS, n (\%) & $6(10.3)$ & $6(4.9)$ & 0.17 \\
\hline Multiorgan failure, n (\%) & $5(8.8)$ & $11(9.0)$ & 0.96 \\
\hline Death, n (\%) & $9(15.3)$ & $7(5.7)$ & 0.035 \\
\hline \multicolumn{4}{|c|}{ Vaccines and Antivirals } \\
\hline Vaccine & $20(37.7)$ & $45(42.5)$ & 0.57 \\
\hline 2009 vaccine & $22(40.7)$ & $49(48)$ & 0.38 \\
\hline Antivirals & $47(90.4)$ & $82(71.3)$ & 0.006 \\
\hline Oseltamivir & $42(82.4)$ & $81(96.4)$ & 0.012 \\
\hline \multicolumn{4}{|c|}{ Virology } \\
\hline A strain & $59(100)$ & $82(70.1)$ & $<0.001$ \\
\hline H1N1 subtype & $30(73,2)$ & $8(100)$ & 0.034 \\
\hline
\end{tabular}

Note: Values are mean \pm SD or number (percentage). Abbreviations: ARDS = acute respiratory distress syndrome; ICU = intensive care unit.

\section{Characteristics of Those Admitted to the Intensive Care Unit}

When the patients admitted to the ICU in both seasons were compared with patients on the general ward, the former were younger, although the difference was not significant $[66 \pm 12$ vs $74 \pm 17$ years] [ $p=0.068$ ], and there was also a higher percentage of men [83.3\% vs. 49.7\%] [p = 0.007]. The time from symptom onset until hospital admission was $4 \pm 3$ days, with a longer length of hospital stay for those who required ICU admission [25 \pm 20 days], compared with $11 \pm 9$ days for those who did not [p $=0.013]$. Appendix Table 2 includes the baseline characteristics of those admitted to the ICU and the general ward. It also confirms that complications were more frequent in the ICU, except bacterial superinfection for which no statistical differences were found. Five [31.5\%] cases were vaccinated, the same percentage that received the 2009-2010 season vaccine. Fourteen patients received antiviral treatment [87.5\%], all oseltamivir, for $7 \pm 2$ days, compared with 5 \pm 2 in those patients who were not admitted to the ICU [p $=0.006]$. Seventeen patients [100\% of the cases analysed] had influenza A infection confirmed, six of whom [75\% of those who were subtyped] were subtype A [H1N1] pm09 (Appendix Table 2). Independent risk factors for ICU admission were male sex [OR 0.173 [0.0320.936], $\mathrm{p}=0.042$ ] and ARDS [OR 96.263 [14.834-624.697], $\mathrm{p}<$ 0.001] (Appendix Table 2).

Appendix Table 2: Baseline characteristics of ICU and non-ICU patients.

\begin{tabular}{|c|c|c|c|c|c|}
\hline & ICU Admission (n, \%) & Conventional ward (n, \%) & $\mathbf{p}$ & Odds ratio (CI 95\%) & $\mathbf{p}$ \\
\hline Total of patients & 18 & 159 & - & & \\
\hline \multicolumn{6}{|c|}{ Baseline Characteristics } \\
\hline Age & $66 \pm 12$ & $74 \pm 17$ & 0.068 & & \\
\hline Sex, male & $15(83.3)$ & $79(49.7)$ & 0.007 & $0.173(0.032-0.936)$ & 0.042 \\
\hline Chronic lung disease, $\mathrm{n}(\%)$ & 7 (38.9) & $70(44.0)$ & 0.677 & & \\
\hline Diabetes mellitus, n (\%) & $3(17.6)$ & $31(19.6)$ & 0.843 & & \\
\hline Chronic kidney disease, n (\%) & $2(11.8)$ & $27(17)$ & 0.567 & & \\
\hline Chronic heart disease, n (\%) & $11(61.1)$ & $80(51.3)$ & 0.429 & & \\
\hline Immunodeficiency, n (\%) & $8(44.4)$ & $46(28.9)$ & 0.188 & & \\
\hline
\end{tabular}




\begin{tabular}{|c|c|c|c|c|c|}
\hline Obesity, n (\%) & $3(16.7)$ & $16(10.1)$ & 0.419 & & \\
\hline Chronic liver disease, $\mathrm{n}(\%)$ & $1(5.6)$ & $15(9.4)$ & 0.563 & & \\
\hline Pregnancy, n (\%) & $0(0)$ & $0(0)$ & - & & \\
\hline \multicolumn{6}{|c|}{ Hospital Stay and Complications } \\
\hline $\begin{array}{l}\text { Latency (symptoms - } \\
\text { admission), days }\end{array}$ & $4 \pm 3$ & $4 \pm 4$ & 0.87 & & \\
\hline Hospital stay, days & $25 \pm 20$ & $11 \pm 9$ & 0.013 & & \\
\hline Bacterial superinfection & $8(66.7)$ & $66(50.8)$ & 0.292 & & \\
\hline Pneumonia & $9(50.0)$ & $43(27.4)$ & 0.047 & & \\
\hline ARDS & $9(50)$ & $2(1.3)$ & 0 & $\begin{array}{l}96.263(14.834- \\
624.697)\end{array}$ & 0 \\
\hline Multiorgan failure & $8(44.4)$ & $7(4.5)$ & 0 & & \\
\hline Death & $4(22.2)$ & $11(7.0)$ & 0.056 & & \\
\hline \multicolumn{6}{|c|}{ Vaccines and Antivirals } \\
\hline Vaccine & $5(31.5)$ & $59(42.4)$ & 0.389 & & \\
\hline 2009 vaccine & $5(35.7)$ & $63(45.7)$ & 0.476 & & \\
\hline Antivirals & $14(87.5)$ & $110(75.3)$ & 0.246 & & \\
\hline Oseltamivir & $14(100.0)$ & $104(89.7)$ & 0.237 & & \\
\hline $\begin{array}{l}\text { Duration of antiviral treatment, } \\
\text { days }\end{array}$ & $7 \pm 2$ & $5 \pm 2$ & 0.006 & & \\
\hline \multicolumn{6}{|c|}{ Virology } \\
\hline A strain & $17(100.0)$ & $120(87.4)$ & $0.004^{*}$ & & \\
\hline H1N1 subtype & $6(75)$ & $31(52.5)$ & 0.056 & & \\
\hline
\end{tabular}

\section{Discussion}

It is estimated that around 5-10\% of confirmed influenza cases require ICU admission [2,5]. This is one of the factors that further increases the economic cost of influenza admissions due to the longer length of stay, as we have also confirmed, and increased use of other health resources $[15,16]$. In addition, it also involves greater morbidity and mortality, as previously described, with a higher percentage of deaths [22\% vs. $7 \%$, admitted to the ICU vs. general ward]. For this reason, we wanted to better understand the characteristics of confirmed influenza cases admitted to the ICU. The 2013-2014 season accounted for a higher percentage of patients admitted to the ICU compared with the subsequent season [13.6\% vs. $8.5 \%$ ]. This finding agrees with the latest document published by the SISS, the epidemiological influenza surveillance body in Spain, which states that the season with the highest number of ICU admissions since the 2009 influenza A H1N1 pandemic in Spain was 2013-2014 [17]. Nonetheless, the influenza epidemic of 20142015 was considered one of the most severe in recent years after the 2009 pandemic, especially due to the higher hospitalisation and mortality rates mainly in patients over 64 years [17].

One of our main postulations is that male sex is a risk factor for ICU admission. Other series have shown conflicting results. Other Spanish cohorts have described prevalence similar to ours [56-73\% of men admitted to the ICU] $[18,19]$. However, other cohorts such as that of the ANZIC group et al. [2] in Australia and New Zealand and that of Beumer et al. [5] in Norway have shown very similar percentages for both sexes [52-55\%]. Research has suggested that, globally, women of childbearing age have a higher incidence of serious disease with the influenza A, H5N1 and H7N9 viruses, as seen in the 2009 A [H1N1] pandemic, while prepubertal males and the elderly are more susceptible to serious disease in epidemic flu $[2,10]$. Among comorbidities, $38.9 \%$ of patients had chronic respiratory diseases, although there were no differences between the groups on the general ward or in the ICU. This is a classic risk factor for influenza severity, probably due to local immune disorders and the physical barriers and mucociliary dysfunction typical of lung diseases, along with a high proportion of elderly patients [19].

Obesity has been added in recent years as a risk factor, both for seasonal and pandemic influenza. In the 2009 A [H1N1] pandemic, about $50 \%$ of cases had a BMI greater than $30 \mathrm{~kg} / \mathrm{m} 2$ and the frequency of obese patients with influenza in the ICU has increased every year [19]. This metabolic disease is associated with hyperinsulinaemia, hyperleptinaemia and nutritional dysregulation, which seems to be related to a proinflammatory microenvironment that impairs the immune response to the influenza virus, as well as the response to influenza vaccination, despite having an equal serological response to vaccination [20]. Regarding complications, pneumonia is one of the most frequent and severe, involving admission to the ICU and contributing substantially to the morbimortality of the infection, especially in those older than 65 [21]. Some of the coadjutant aetiological mechanisms detected are: the destruction of the respiratory epithelium by the virus, as well as the activity of its neuraminidase, both factors that could increase 
bacterial adhesion; inflammatory responses to viral infection, which could upregulate the expression of molecules used as receptors for bacteria; bacterial superinfections promoting immunosuppression; and the synthesis of bacterial virus activating proteases [22].

Other serious complications are ARDS, which was developed in half of the cases and which is described as a risk factor, and multiorgan failure, in $44.4 \%$ of cases. Despite the development of novel lung-protective mechanical ventilation strategies and the use of extracorporeal membrane oxygenation, influenza-induced ARDS is a fatal complication. The mechanisms of its development are not yet clear, but it has been postulated that the death of alveolar epithelial cells produces cytokines, which can attract leukocytes and activate adjacent epithelial cells. This leads to cellular infiltration and produces reactive species of oxygen and nitric oxide believed, on the one hand, to damage the mucociliary barrier and, on the other, to lead to direct apoptosis of epithelial cells. Targeted therapies are often unsuitable for treating the disease since lung damage has been found to persist after infection. However, this theory could justify therapeutic intervention to control the host response [23-26].

Vaccination has been shown to reduce the frequency of serious complications, independently of age and comorbidities $[13,20]$. However, in our series just $31.5 \%$ of ICU patients were vaccinated. This result is in line with recorded vaccination rates, which, although having increased in recent years, remain poor [27]. Every ICU patient in our cohort was infected with influenza A and $75 \%$ of them had subtype A [H1N1] pm09 compared with 52\% in nonICU patients. Furthermore, if we analyse both seasons separately, in 2013-14 there was a trend towards an increase in influenza A [H1N1] pm09 compared with 2014-15, in line with the SISS data [13]. Though we must interpret the results with caution given the limitations of the information extracted from any surveillance system, this supports the greater severity of influenza A [H1N1] infection, responsible for the 2009 pandemic. It is frequently the case that, in epidemic seasons, the number of those with virus $\mathrm{A}$ infection is higher than those with virus B [5]. Nevertheless, some studies have shown that the B and A strains produce similar rates of pneumonia and death [24].

Finally, $87.5 \%$ of the total patients and $100 \%$ of ICU patients received antiviral treatment. It is a much higher proportion than in another Spanish series in which, although adherence is a factor associated with lower mortality [HR $=0.47$ ], just $41.6 \%$ of patients received antiviral treatment [28]. Probably the high percentage in our cohort is explained by the protocols of our centre that recommend the use of antivirals in every patient admitted; the length of treatment in the ICU is accordingly longer [29,30]. This study has several limitations. First, it is a single-centre study with a limited number of cases, and consequently the results should be extrapolated with caution to a larger population. Second, since we only collected the variables recommended by the SISS, some interesting aspects have not been addressed. Furthermore, since the data were obtained retrospectively from medical records, we had some lost data. Lastly, long-term morbidity and mortality and readmissions have not been estimated, so this study probably underestimates disease severity.

\section{Conclusion}

Male sex and the development of ARDS are two independent risk factors for admission to the ICU, which occurs in up to $10 \%$ of all those hospitalised for influenza. These patients have more complications, a longer hospital stay, and higher detection rates of influenza A virus compared with those on a conventional ward. We must progress the development of specific therapies, as well as influenza vaccination campaigns, to try to reduce ICU admission, since this involves high morbidity and mortality and significant associated social and healthcare costs.

\section{Funding}

We have not received any sources of funding.

\section{Competing Interests}

The authors declare that they have no conflicts of interest regarding the manuscript.

\section{Acknowledgment}

To the Preventive Medicine and Microbiology Department of La Paz University Hospital for providing the data from the documents of the patients admitted during the influenza seasons.

\section{References}

1. Iuliano AD, Roguski KM, Chang HH, David J Muscatello, Rakhee Palekar, et al. (2018) Estimates of global seasonal influenza-associated respiratory mortality: a modelling study, Lancet 391: 1285-1300.

2. ANZIC Influenza Investigators, Webb SA, Pettilä V, Ian Seppelt, Rinaldo Bellomo, et al. (2009) Critical care services and 2009 H1N1 influenza in Australia and New Zealand. N. Engl. J. Med. 361: 1925-1934.

3. Taylor G, Abdesselam K, Pelude L, Fernandes R, Mitchell R et al. (2016) Epidemiological features of influenza in Canadian adult intensive care unit patients. Epidemiol. Infect 144: 741-750.

4. Jamieson DJ, Honein MA, Rasmussen SA, David L Swerdlow, Matthew S Biggerstaff, et al. (2009) H1N1 2009 influenza virus infection during pregnancy in the USA. Lancet 374: 451-458.

5. Beumer MC, Koch RM, Van Beuningen D, A M OudeLashof, F L van de Veerdonk, et al. (2019) Influenza virus and factors that are associated with ICU admission, pulmonary co-infections and ICU mortality. J Crit Care 50: 59-65.

6. Rello J, Rodríguez A, Ibañez P, Javier Cebrian, Asunción Marques, José Guerrero, et al. (2009) Intensive care adult patients with severe respiratory failure caused by Influenza A (H1N1) v in Spain. Crit Care 13: R148.

7. Thompson WW, Shay DK, Weintraub E, Lynnette Brammer, Nancy Cox, et al (2003) Mortality associated with influenza and respiratory syncytial virus in the United States. JAMA 289: 179-186.

8. Thompson WW, Shay DK, Weintraub E, Lynnette Brammer, Carolyn B Bridges, et al. (2004) Influenza-associated hospitalizations in the United States. JAMA 292: 1333-1340. 
9. Cohen C, Simonsen L, Kang JW, Mark Miller, Jo Mc Anerney, et al. (2010) Elevated influenza-related excess mortality in South African elderly individuals, 1998-2005. Clin. Infect. Dis 51: 1362-1369.

10. Louie JK, Acosta M, Winter K, Shilpa Gavali, Robert Schechter, et al. (2009) Factors associated with death or hospitalization due to pandemic 2009 influenza A(H1N1) infection in California. JAMA 302: 1896-1902.

11. Pérez-Padilla R, D de la Rosa-Zamboni, S Ponce, Mauricio Hernandez, Francisco Quiñones-Falconi, et al. (2009) Pneumonia and respiratory failure from swine-origin influenza A (H1N1) in Mexico. N. Engl. J. Med. 361: 680-689.

12. Ortiz JR, Neuzil KM, Shay DK, Tessa C Rue, Moni B Neradilek, et al. (2014) The burden of influenza-associated critical illness hospitalizations. Crit Care Med 42 (2014) 2325-2332.

13. (2014) Spanish Influenza Surveillance System. Spanish Influenza Surveillance Report. Season 2013-2014 (from week 40/2013 to week 20/2014). Carlos III Health Institute, 2014.

14. Carlos III Health Institute. Spanish Influenza Surveillance Report. Season 2014-2015 (from week 40/2014 to week 20/2015). Spanish Influenza Surveillance System.

15. Hernes S, Quarsten H, Hamre R, Hagen E, Bjorvatn B, et al. (2013) A comparison of nasopharyngeal and oropharyngeal swabbing for the detection of influenza virus by real-time PCR. Eur. J. Clin. Microbiol. Infect. Dis 32: 381-385.

16. Chan YK, Wong RY, Ip M, Lee NL, You JH (2017) Economic outcomes of influenza in hospitalized elderly with and without ICU admission. Antivir Ther 22: 173-177.

17. Carlos III Health Institute. Spanish Influenza Surveillance Report. Season 2017-2018 (from week 40/2017 to week 20/2018). Spanish Influenza Surveillance System.

18. Pérez-Carrasco M, Lagunes L, Antón A, César Labordaa, Tomás Pumarolab, et al. (2016) Influenza infection in the intensive care unit: Four years after the 2009 pandemic. Enferm Infecc Microbiol Clin 34: 177-183.

19. Veerapandian R, Snyder JD, Samarasinghe AE (2018) Influenza in asthmatics: for better or for worse? Front. Immunol 9: 1843-1858.

20. Green WD, Beck MA (2017) Obesity Impairs the Adaptive Immune Response to Influenza Virus. Ann. Am. Thorac Soc 14: S406-S409.

ISSN: 2574-1241

DOI: $10.26717 / B J S T R .2020 .29 .004765$

Ester Zamarrón de Lucas. Biomed J Sci \& Tech Res

This work is licensed under Creative

Commons Attribution 4.0 License

Submission Link: https://biomedres.us/submit-manuscript.php
21. Chertow DS, Memoli MJ (2013) Bacterial coinfection in influenza: a grand rounds review. JAMA 309: 275-82

22. Metersky ML, Masterton RG, Lode H, File TM, Babinchak T (2012) Epidemiology, microbiology, and treatment considerations for bacterial pneumonia complicating influenza. Int. J. Infect. Dis 16: e321-31.

23. Brun-Buisson C, Minelli C, Bertolini G, Luca Brazzi, Jorge Pimentel, et al. (2004) Epidemiology and outcome of acute lung injury in European intensive care units. Results from the ALIVE study. Intens. Care. Med 30: 51-61.

24. Li G, Yilmaz M, Kojicic M, Evans Fernández-Pérez, Raed Wahab, et al. (2009) Outcome of critically ill patients with influenza virus infection. J. Clin. Virol. 46: 275-278.

25. To KK, Hung IF, Li IW, Kar-Lung Lee, Chi-Kwan Koo, et al. (2010) Delayed clearance of viral load and marked cytokine activation in severe cases of pandemic H1N1 2009 influenza virus infection. Clin Infect Dis 50: 850859.

26. Short KR, Kroeze EJ, Fouchier RAM, Kuiken T (2014) Pathogenesis of influenza-induced acute respiratory distress syndrome. Lancet. Infect Dis 14: 57-69.

27. Catania J, Loretta LG, Govert JA, Hollingsworth JW, Wolfe CR (2014) Highly Intensive Care Unit Admission Rate for 2013-2014 Influenza Is Associated with a Low Rate of Vaccination. Am. J. Respir. Crit. Care Med 189: 485-487.

28. Canadell L, Martín-Loeches I, Díaz E, Grau S, J C Yebenes, et al. (2015) Degree of adherence to recommended antiviral treatment during the pandemic and post-pandemic periods of influenza A(H1N1)pdm09 in 148 intensive care units in Spain. Med. Intensiva 39: 222-233.

29. Uyeki TM, Bernstein HH, Bradley JS, Janet A Englund, Thomas M File, et al. (2019) Clinical Practice Guidelines by the Infectious Diseases Society of America: 2018 Update on Diagnosis, Treatment, Chemoprophylaxis, and Institutional Outbreak Management of Seasonal Influenza A. Clin Infect Dis 68: 895-902.

30. Noel ZR, Bastin MLT, Montgomery AA, Flannery AH (2017) Comparison of High-Dose Versus Standard Dose Oseltamivir in Critically Ill Patients with Influenza. J Intensive Care Med 32: 574-577.

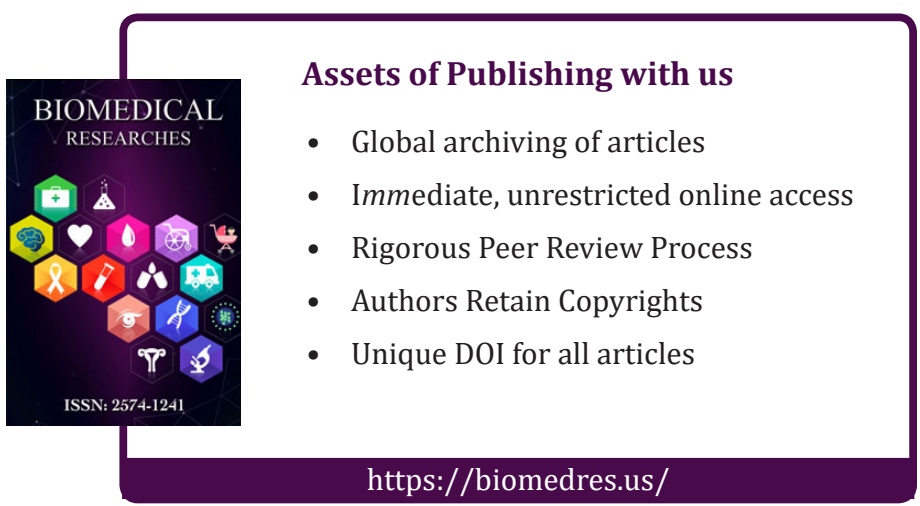

